\title{
Predictors of Cerebral Aneurysm Rupture after Coil Embolization: Single-Center Experience with Recanalized Aneurysms
}

\author{
(D) Y. Funakoshi, (DH. Imamura, (D). Tani, (D). Adachi, (D). Fukumitsu, (D). Sunohara, (D). Omura, (D). Matsui, (D) N. Sasaki, \\ (D) T. Fukuda, (D) R. Akiyama, (D). Horiuchi, (D) S. Kajiura, (D). Shigeyasu, (D) K. lihara, and DN. Sakai
}

\begin{abstract}
BACKGROUND AND PURPOSE: Recanalization after coil embolization is widely studied. However, there are limited data on how recanalized aneurysms rupture. Herein, we describe our experience with the rupture of recanalized aneurysms and discuss the type of recanalized aneurysms at greatest rupture risk.
\end{abstract}

MATERIALS AND METHODS: A total of 426 unruptured aneurysms and 169 ruptured aneurysms underwent coil embolization in our institution between January 2009 and December 2017. Recanalization occurred in 38 (8.9\%) of 426 unruptured aneurysms (unruptured group) and 37 (21.9\%) of 169 ruptured aneurysms (ruptured group). The Modified Raymond-Roy classification on DSA was used to categorize the recanalization type. Follow-up DSA was scheduled until 6 months after treatment, and follow-up MRA was scheduled yearly. If recanalization was suspected on MRA, DSA was performed.

RESULTS: In the unruptured group, the median follow-up term was 74.0 months. Retreatment for recanalization was performed in 18 aneurysms. Four of 20 untreated recanalized aneurysms ( $0.94 \%$ of total coiled aneurysms) ruptured. In untreated recanalized aneurysms, class IIIb aneurysms ruptured significantly more frequently than class II and IIla $(P=.025)$. In the ruptured group, the median follow-up term was 28.0 months. Retreatment for recanalization was performed in 16 aneurysms. Four of 21 untreated recanalized aneurysms $(2.37 \%$ of total coiled aneurysms) ruptured. Class IIIb aneurysms ruptured significantly more frequently than class II and IIla $(P=.02)$.

CONCLUSIONS: The types of recanalization after coil embolization may be predictors of rupture. Coiled aneurysms with class IIIb recanalization should undergo early retreatment because of an increased rupture risk.

ABBREVIATIONS: AcomA = anterior communicating artery; PcomA = posterior communicating artery

$E^{\mathrm{n}}$

ndovascular coiling of cerebral aneurysms is widely performed, with continued improvement in related techniques and devices. ${ }^{1,2}$ However, an important problem with endovascular coiling is recanalization after coil embolization. Coiled aneurysms that show major recanalization require additional coiling to prevent rupture. The incidence of recanalization after coiling ranges from $6.1 \%$ to $33.6 \%,{ }^{3,4}$ and the reported risk factors for recanalization include aneurysm morphologic features, coil compaction and/or migration, and various endovascular embolization techniques. ${ }^{3-5}$

Received December 15, 2019; accepted after revision February 22, 2020 From the Department of Neurosurgery (Y.F., H.I., S.T., H.A., R.F., T.S., Y.O., Y.M N.Sasaki, T.F., R.A., K.H., S.K., M.S., N.Sakai), Kobe City Medical Center General Hospital, Kobe, Japan; and Department of Neurosurgery (K.I.), Graduate School of Medical Sciences, Kyushu University, Fukuoka, Japan.

Please address correspondence to Yusuke Funakoshi, MD, Department of Neurosurgery, Graduate School of Medical Sciences, Kyushu University, 3-1-1 Maidashi, Higashi-ku, Fukuoka 812-8582, Japan; e-mail: sflwan0610@gmail.com

Indicates article with supplemental on-line table.

http://dx.doi.org/10.3174/ajnr.A6558
Although recanalization after coil embolization has been previously evaluated, there are insufficient data on the way in which recanalized aneurysms rupture. Thus, in the present study, we describe our experience with the rupture of aneurysms that have recanalized after coil embolization in Kobe City Medical Center General Hospital and discuss the type of recanalized aneurysms at greatest risk of rupture and the appropriate timing of followup angiography and retreatment.

\section{MATERIALS AND METHODS}

\section{Patient and Aneurysm Characteristics}

Between January 2009 and December 2017, coil embolization was performed in a total of 426 unruptured aneurysms and 169 ruptured aneurysms in our institution, excluding fusiform aneurysms, dissecting aneurysms, infectious aneurysms, and aneurysms combined with arteriovenous malformations or Moyamoya disease. Aneurysms that underwent parent artery occlusion and that were treated with an off-label stent used in a clinical trial and a stent in the acute phase of rupture, recanalized aneurysms previously 
Table 1: Patient and aneurysm characteristics, volume embolization ratio, use of stents, and follow-up term ${ }^{\text {a }}$

\begin{tabular}{|c|c|c|c|c|}
\hline & \multicolumn{2}{|c|}{ Unruptured Group } & \multicolumn{2}{|c|}{ Ruptured Group } \\
\hline & $\begin{array}{l}\text { All Aneurysms } \\
(n=426)\end{array}$ & $\begin{array}{l}\text { Recanalized Aneurysms } \\
\qquad(n=38)\end{array}$ & $\begin{array}{l}\text { All Aneurysms } \\
(n=169)\end{array}$ & $\begin{array}{l}\text { Recanalized Aneurysms } \\
\qquad(n=37)\end{array}$ \\
\hline \multicolumn{5}{|c|}{ Patient characteristic } \\
\hline Age $(y r)$ & $63.0(52.0-70.0)$ & $65.0(49.8-71.3)$ & $66.0(52.0-77.5)$ & $59.0(44.5-76.5)$ \\
\hline Male sex & $105(24.6 \%)$ & $6(15.8 \%)$ & $56(33.1 \%)$ & $10(27.0 \%)$ \\
\hline \multicolumn{5}{|l|}{ Aneurysm location } \\
\hline ICA-cavernous & $12(2.8 \%)$ & $2(5.3 \%)$ & $0(0.0 \%)$ & $0(0.0 \%)$ \\
\hline ICA-paraclinoid & $188(44.1 \%)$ & $9(23.7 \%)$ & $5(3.0 \%)$ & $2(5.4 \%)$ \\
\hline ICA-PcomA & 49 (11.5\%) & $9(23.7 \%)$ & $55(32.5 \%)$ & $16(43.2 \%)$ \\
\hline ICA-AchoA & $10(2.3 \%)$ & $0(0.0 \%)$ & $13(7.7 \%)$ & $4(10.8 \%)$ \\
\hline ICA-bifurcation & $11(2.6 \%)$ & $2(5.3 \%)$ & $3(1.8 \%)$ & $0(0.0 \%)$ \\
\hline MCA & $6(1.4 \%)$ & $0(0.0 \%)$ & $4(2.4 \%)$ & $0(0.0 \%)$ \\
\hline AcomA & $66(15.5 \%)$ & $1(2.6 \%)$ & $57(33.7 \%)$ & $11(29.7 \%)$ \\
\hline VA & $15(3.5 \%)$ & $4(10.5 \%)$ & $8(4.7 \%)$ & $1(2.7 \%)$ \\
\hline $\mathrm{BA}-\mathrm{SCA}$ & $16(3.8 \%)$ & $2(5.3 \%)$ & $2(1.2 \%)$ & $1(2.7 \%)$ \\
\hline BA-bifurcation & $41(9.6 \%)$ & $9(23.7 \%)$ & $12(7.1 \%)$ & $2(5.4 \%)$ \\
\hline Others & $12(2.8 \%)$ & $0(0.0 \%)$ & $10(5.9 \%)$ & $0(0.0 \%)$ \\
\hline \multicolumn{5}{|l|}{ Aneurysm size } \\
\hline Dome & $6.2(4.9-8.4)$ & 10.1 (7.0-14.1) & $6.5(5.0-9.3)$ & $7.7(5.4-13.0)$ \\
\hline Neck & $3.8(2.9-5.1)$ & $5.9(4.7-7.7)$ & $3.2(2.4-4.2)$ & $4.0(2.7-5.9)$ \\
\hline \multicolumn{5}{|c|}{ Endovascular procedures } \\
\hline VER & $26.9(21.9-32.8)$ & $23.0(18.0-29.2)$ & $25.8(19.8-33.2)$ & 23.7 (18.9-29.5) \\
\hline Without stent & $240(56.3 \%)$ & $19(50.0 \%)$ & $169(100.0 \%)$ & $37(100.0 \%)$ \\
\hline With stent & 186 (43.7\%) & 19 (50.0\%) & $0(0.0 \%)$ & $0(0.0 \%)$ \\
\hline \multicolumn{5}{|l|}{ Follow-up } \\
\hline Duration (mo) & $58.5(24.0-86.0)$ & $74.0(30.5-96.3)$ & $18.0(3.0-48.0)$ & $28.0(10.0-56.0)$ \\
\hline
\end{tabular}

Note:-AchoA indicates anterior choroidal artery; VA, vertebral artery; BA, basilar artery; SCA, superior cerebellar artery; VER, volume embolization ratio.

${ }^{a}$ Unruptured group indicates unruptured aneurysms that underwent coil embolization; ruptured group, ruptured aneurysms that underwent coil embolization. Data are Unruptured Group ( $n=426$ ): Recanalization after coil embolization occurred in 38 of 426 unruptured aneurysms. Ruptured Group ( $n=169)$ : Recanalization after coil embolization occurred in 37 of 169 ruptured aneurysms.

treated with coiling, and aneurysms that reruptured in the acute phase ( $<1$ month after the initial rupture) were excluded from the present study. Recanalization after coil embolization occurred in 38 of 426 (8.9\%) unruptured aneurysms (unruptured group) and 37 of 169 (21.9\%) ruptured aneurysms (ruptured group). Table 1 summarizes the characteristics of the patients and recanalized aneurysms, endovascular procedures, and follow-up term in these 2 groups compared with all patients and aneurysms.

The present investigation was approved by our local ethics committee (institutional review board of Kobe City Medical Center General Hospital). The study was conducted in accordance with the 1964 Declaration of Helsinki (as revised in Fortaleza, Brazil, October 2013).

\section{Perioperative Antiplatelet Management}

Patients undergoing coil embolization for unruptured aneurysms were generally administered dual-antiplatelet therapy with $100 \mathrm{mg}$ of aspirin and $75 \mathrm{mg}$ of clopidogrel daily for at least 7 days before the procedure. Either aspirin or clopidogrel was decreased gradually from 6 months after the procedure and discontinued after at least 1 year. Single-antiplatelet therapy was generally discontinued after 1 or 2 years. When stent-assisted coil embolization was performed, antiplatelet activity was assessed using aspirin and P2Y12 assays (VerifyNow; Accumetrics) on the day before the procedure. When the aspirin reaction unit measurements were $>550$, the aspirin dose was increased to $200 \mathrm{mg}$ daily. When the P2Y12 reaction unit measurements were $>220$, a loading dose of $20 \mathrm{mg}$ of prasugrel was given, and the dose was then decreased to $3.75 \mathrm{mg}$ from the following day. Prasugrel was decreased gradually from 6 months after the procedure. Although prasugrel and either aspirin or clopidogrel were discontinued after 1 year, single-antiplatelet therapy was continued as a life-long treatment. Patients undergoing coil embolization for ruptured aneurysms were generally administered single-antiplatelet therapy with aspirin or cilostazol. Single-antiplatelet therapy was discontinued depending on the DSA findings.

\section{Endovascular Procedures}

Preoperative DSA findings were used to determine the best approach and technique for the endovascular procedure (ie, simple technique, double-catheter technique, balloon-assisted coil embolization, or stent-assisted coil embolization). The procedure was performed by a neurovascular team, including a board-certified neuroendovascular surgeon. The procedure for unruptured aneurysms was generally performed with the patient under local anesthesia, because neurologic evaluation can be performed during the procedure. The procedure for ruptured aneurysms was performed with the patient under general anesthesia. All patients received heparin after an arterial puncture to maintain an elevated activated clotting time of approximately 300 seconds during the procedure for unruptured aneurysms and approximately 250 seconds for ruptured aneurysms. The volume embolization ratio was measured on DSA after the procedure, and the angiographic findings were evaluated. 


\section{Evaluation of Coiled Aneurysms}

The Raymond-Roy occlusion classification is the standard for evaluating aneurysm occlusion, while the Modified RaymondRoy classification was recently reported to be a predictor of progressive occlusion or recurrence (Fig 1). ${ }^{6}$ In the Modified Raymond-Roy classification, complete obliteration is defined as class I, a residual neck is defined as class II, and a residual aneurysm is defined as class III. ${ }^{6}$ Class III is further separated into class IIIa (contrast within the coil interstices) and IIIb (contrast along the aneurysm wall). ${ }^{6}$ The present study used the Modified Raymond-Roy classification to evaluate aneurysm occlusion and recanalization. Any further filling of the aneurysm sac across

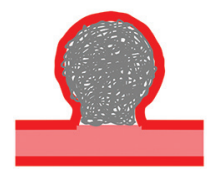

class I

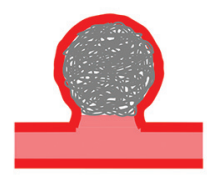

class II

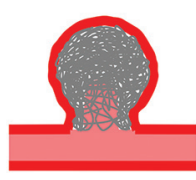

class IIIa

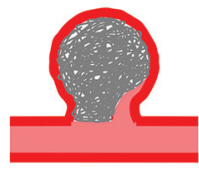

class IIIb

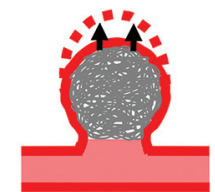

aneurysm growth

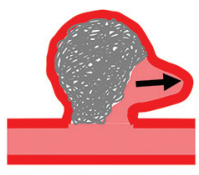

appearance of bleb
FIG 1. Illustration of the Modified Raymond-Roy classification and additional definitions of the type of recanalization used in the present study. Class I: complete obliteration; class II: residual neck; class IIla: residual aneurysm with contrast within the coil interstices; class IIIb: residual aneurysm with contrast along the aneurysm wall. The appearance of new blebs was distinguished from an increase in the diameter of the coiled aneurysm. Except for the appearance of new blebs, an increase in the diameter of the coiled aneurysm was termed "aneurysm growth." time on follow-up DSA was termed "recanalization." The appearance of new blebs was distinguished from an increase in the diameter of the coiled aneurysm. Except for the appearance of new blebs, an increase in the diameter of the coiled aneurysm was termed "aneurysm growth" (Fig 1).

Two observers, who were board-certified neuroendovascular surgeons, evaluated aneurysm occlusion and recanalization using the Modified Raymond-Roy classification, and 1 investigator evaluated these parameters twice to verify inter- and intrarater reliability.

\section{Follow-Up}

In the unruptured group, follow-up DSA was scheduled at 6 months after treatment, and follow-up MRA (using $\geq 1.5 \mathrm{~T}$ magnet strength) was scheduled yearly. In the ruptured group, follow-up DSA was generally scheduled for 1 week after treatment to evaluate vasospasm and for 1 month after treatment to detect early recanalization. From 6 months after treatment, follow-up evaluations were performed as described for the unruptured group. In principle, the diagnosis of recanalization was based only on DSA findings. If recanalization was suspected on follow-up MRA, DSA was performed. When recanalization was identified on follow-up DSA, the patient was scheduled to undergo retreatment or an earlier follow-up DSA.

\section{Statistical Analysis}

Statistical analyses were performed using statistical software (JMP software, Version 14; SAS Institute). Sex, aneurysm location, use of a stent, type of recanalization, aneurysm growth, and the appearance of new blebs were evaluated using the $\chi^{2}$ test or the Fisher exact test. Age, aneurysm dome diameter, aneurysm neck size, and volume embolization ratio were analyzed using the Mann-Whitney $U$ test. $P<.05$ was considered statistically significant.

\section{Table 2: Outcomes of aneurysms and patients}

\begin{tabular}{lcc}
\hline & Unruptured Group & \\
\hline Type of recanalization on final DSA & & Ruptured Group $^{\mathrm{a}}$ \\
Class II & $3(7.9 \%)$ & \\
Class IIla & $12(31.6 \%)$ & $7(18.9 \%)$ \\
Class IIIb & $23(60.5 \%)$ & $7(18.9 \%)$ \\
Aneurysm growth & $12(31.6 \%)$ & $23(62.2 \%)$ \\
Appearance of bleb & $2(5.3 \%)$ & $3(8.1 \%)$ \\
Retreatment & $18(47.4 \%)$ & $1(2.7 \%)$ \\
Rupture & $4(10.5 \%)$ & $16(43.2 \%)$ \\
Rupture risk (Vaneurysm) & $0.94 \%$ & $4(10.8 \%)$ \\
Rupture risk (/yr) & $0.20 \%$ & $2.37 \%$ \\
Final mRS score without ruptured & & $0.97 \%$ \\
recanalized aneurysm & \\
$0-2$ & $31(91.2 \%)$ & \\
$3-4$ & $1(2.9 \%)$ & $21 / 33(63.6 \%)$ \\
$5-6$ & $2(5.9 \%)$ & $6 / 33(18.2 \%)$ \\
Final mRS score with ruptured & & $6 / 33(18.2 \%)$ \\
recanalized aneurysm ${ }^{\mathrm{c}}$ & $2(50.0 \%)$ & \\
$0-2$ & $0(0.0 \%)$ & $1(25.0 \%)$ \\
$3-4$ & $2(50.0 \%)$ & $2(50.0 \%)$ \\
$5-6$ & & $1(25.0 \%)$ \\
\hline
\end{tabular}

\footnotetext{
a Unruptured Group ( $n=38$ ); Ruptured Group ( $n=37)$.

b Unruptured Group ( $n=34)$; Ruptured Group $(n=33)$.

c Unruptured Group $(n=4)$; Ruptured Group $(n=4)$.
}

\section{RESULTS}

\section{Outcomes of Aneurysms and Patients}

Outcomes of aneurysms and patients are summarized in Table 2. In the unruptured group, the median followup term of recanalized aneurysms was 74.0 months. The type of recanalization on follow-up DSA, the timing of retreatment and rupture, and the type of recanalization immediately before retreatment and rupture are shown in Table 3. From a total of 38 recanalized aneurysms, the type of recanalization on final DSA was classified as class II in 3 (7.9\%) aneurysms, class IIIa in 12 (31.6\%), and class IIIb in 23 (60.5\%). On follow-up DSA, aneurysm growth was identified in 12 (31.6\%) aneurysms, and the appearance of new blebs, in 2 (5.3\%) aneurysms. Retreatment was performed in 18 (47.4\%) aneurysms, 
Table 3: Type of aneurysm occlusion and recanalization on follow-up DSA, the timing of retreatment and rupture, and the type of recanalization immediately before retreatment and rupture in the unruptured group ${ }^{a}$

\begin{tabular}{|c|c|c|c|c|c|c|c|c|c|c|}
\hline & $\begin{array}{l}\text { Initial } \\
(n=38) \\
(n=38)\end{array}$ & $\begin{array}{l}6 \text { Months } \\
(n=36) \\
(n=38)\end{array}$ & $\begin{array}{l}1 \text { Year } \\
(n=16) \\
(n=37)\end{array}$ & $\begin{array}{l}2 \text { Years } \\
(n=3) \\
(n=35)\end{array}$ & $\begin{array}{l}3 \text { Years } \\
(n=0) \\
(n=26)\end{array}$ & $\begin{array}{l}4 \text { Years } \\
(n=0) \\
(n=26)\end{array}$ & $\begin{array}{c}5 \text { Years } \\
(n=1) \\
(n=23)\end{array}$ & $\begin{array}{l}6 \text { Years } \\
(n=1) \\
(n=22)\end{array}$ & $\begin{array}{l}7 \text { Years } \\
(n=0) \\
(n=16)\end{array}$ & $\begin{array}{l}8 \text { Years } \\
(n=1) \\
(n=13)\end{array}$ \\
\hline \multicolumn{11}{|c|}{$\begin{array}{l}\text { Type of aneurysm occlusion } \\
\text { and recanalization }\end{array}$} \\
\hline 1 & 5 & 2 & 0 & 0 & 0 & 0 & 0 & 0 & 0 & 0 \\
\hline II & 10 & 4 & 1 & 0 & 0 & 0 & 0 & 0 & 0 & 0 \\
\hline IIla & 12 & 13 & 9 & 1 & 0 & 0 & 0 & 1 & 0 & 0 \\
\hline IIIb & 11 & 17 & 6 & 2 & 0 & 0 & 1 & 0 & 0 & 1 \\
\hline \multicolumn{11}{|c|}{$\begin{array}{l}\text { Type of recanalization of } \\
\text { retreated recanalized } \\
\text { aneurysms }\end{array}$} \\
\hline IIla & 0 & 1 & 3 & 0 & 0 & 0 & 0 & 1 & 0 & 0 \\
\hline IIIb & 0 & 8 & 2 & 1 & 0 & 0 & 1 & 0 & 0 & 1 \\
\hline \multicolumn{11}{|c|}{$\begin{array}{l}\text { Type of recanalization of } \\
\text { ruptured recanalized } \\
\text { aneurysms }\end{array}$} \\
\hline IIla & 0 & 0 & 0 & 0 & 0 & 0 & 0 & 0 & 0 & 0 \\
\hline IIIb & 1 & 1 & 1 & 0 & 0 & 0 & 0 & 1 & 0 & 0 \\
\hline
\end{tabular}

${ }^{a}$ The first row of numbers in parentheses indicates the number of cases that underwent follow-up DSA at that time; the second row of numbers in parentheses, the number of cases that underwent follow-up MRA at that time.

Table 4: Type of aneurysm occlusion and recanalization on follow-up DSA, the timing of retreatment and rupture, and the type of recanalization immediately before retreatment and rupture in the ruptured group ${ }^{\mathrm{a}}$

\begin{tabular}{|c|c|c|c|c|c|c|c|c|c|c|}
\hline & $\begin{array}{l}\text { Initial } \\
(n=37) \\
(n=37)\end{array}$ & $\begin{array}{l}1 \text { Week } \\
(n=37) \\
(n=37)\end{array}$ & $\begin{array}{l}1 \text { Month } \\
(n=34) \\
(n=37)\end{array}$ & $\begin{array}{l}6 \text { Months } \\
(n=19) \\
(n=29)\end{array}$ & $\begin{array}{c}1 \text { Year } \\
(n=12) \\
(n=28)\end{array}$ & $\begin{array}{l}2 \text { Years } \\
(n=0) \\
(n=22)\end{array}$ & $\begin{array}{l}3 \text { Years } \\
(n=0) \\
(n=18)\end{array}$ & $\begin{array}{l}4 \text { Years } \\
(n=0) \\
(n=13)\end{array}$ & $\begin{array}{l}5 \text { Years } \\
(n=0) \\
(n=9)\end{array}$ & $\begin{array}{l}6 \text { Years } \\
(n=0) \\
(n=6)\end{array}$ \\
\hline \multicolumn{11}{|c|}{$\begin{array}{l}\text { Type of aneurysm } \\
\text { occlusion and } \\
\text { recanalization }\end{array}$} \\
\hline I & 14 & 9 & 3 & 0 & 0 & 0 & 0 & 0 & 0 & 0 \\
\hline II & 17 & 19 & 13 & 5 & 2 & 0 & 0 & 0 & 0 & 0 \\
\hline Illa & 2 & 2 & 3 & 5 & 3 & 0 & 0 & 0 & 0 & 0 \\
\hline IIIb & 4 & 7 & 15 & 9 & 7 & 0 & 0 & 0 & 0 & 0 \\
\hline \multicolumn{11}{|c|}{$\begin{array}{l}\text { Type of recanalization of } \\
\text { retreated recanalized } \\
\text { aneurysms }\end{array}$} \\
\hline IIla & 0 & 0 & 0 & 2 & 1 & 0 & 0 & 0 & 0 & 0 \\
\hline IIIb & 0 & 0 & 11 & 1 & 1 & 0 & 0 & 0 & 0 & 0 \\
\hline \multicolumn{11}{|c|}{$\begin{array}{l}\text { Type of recanalization of } \\
\text { ruptured recanalized } \\
\text { aneurysms }\end{array}$} \\
\hline IIla & - & - & 0 & 0 & 0 & 0 & 0 & 0 & 0 & 0 \\
\hline IIlb & - & - & 2 & 1 & 0 & 1 & 0 & 0 & 0 & 0 \\
\hline
\end{tabular}

Note:- - indicates not available.

${ }^{a}$ Aneurysms that reruptured in the acute phase $(<1$ month after the initial rupture) were excluded. The first-row of number in parentheses indicates the number of cases that underwent follow-up DSA at that time. The second-row of number in parentheses indicates the number of cases that underwent follow-up MRA at that time.

while 20 (52.6\%) were untreated. The 2 aneurysms with the appearance of new blebs were retreated. Four of the 20 untreated aneurysms ruptured, $0.94 \%$ of the total coiled aneurysms ruptured, and the rupture risk was $0.20 \%$ per year. Thirty-one (91.2\%) of 34 patients without a ruptured recanalized aneurysm had a final mRS of $0-2$, while $2(50.0 \%)$ of 4 patients with a ruptured recanalized aneurysm had a final mRS of $0-2$.

In the ruptured group, the median follow-up term of recanalized aneurysms was 28.0 months. The type of recanalization on followup DSA, the timing of retreatment and rupture, and the type of recanalization immediately before retreatment and rupture are shown in Table 4. From a total of 37 recanalized aneurysms, the type of recanalization on final DSA was classified as class II in 7 (18.9\%) aneurysms, class IIIa in 7 (18.9\%), and class IIIb in 23 (62.2\%). On follow-up DSA, aneurysm growth was identified in 3 (8.1\%) aneurysms, and new blebs appeared in 1 (2.7\%) aneurysm. Retreatment was performed in $16(43.2 \%)$ aneurysms, and 21 (56.8\%) were untreated. The aneurysm with the appearance of new blebs was retreated. Four of the 21 untreated aneurysms ruptured, $2.37 \%$ of the total coiled aneurysms ruptured, and the rupture risk was $0.97 \%$ per year. Twenty-one $(63.6 \%)$ of 33 patients without a ruptured recanalized aneurysm had a final mRS of $0-2$, while $1(25.0 \%)$ of 4 patients with a ruptured recanalized aneurysm had a final mRS of $0-2$.

\section{Factors Associated with Rupture after Coil Embolization}

Factors associated with rupture after coil embolization are summarized in Tables 5 and 6 for the unruptured and ruptured groups, 
Table 5: Factors associated with rupture after coil embolization in untreated recanalized aneurysms in the unruptured group ${ }^{\mathrm{a}}$

\begin{tabular}{|c|c|c|c|}
\hline & \multicolumn{3}{|c|}{ Untreated Recanalized Aneurysms $(n=20)$} \\
\hline & Unruptured $(n=16)$ & Ruptured $(n=4)$ & $P$ Value \\
\hline Age (yr) & $67.0(60.3-72.8)$ & $63.0(55.8-70.3)$ & .570 \\
\hline \multicolumn{4}{|l|}{ Sex } \\
\hline Male & $1(6.3 \%)$ & $1(25.0 \%)$ & .264 \\
\hline Female & $15(93.7 \%)$ & $3(75.0 \%)$ & \\
\hline \multicolumn{4}{|l|}{ Location } \\
\hline ICA & $5(31.2 \%)$ & $1(25.0 \%)$ & .937 \\
\hline ICA-PcomA & $4(25.0 \%)$ & $1(25.0 \%)$ & \\
\hline AcomA & $1(6.3 \%)$ & $0(0.0 \%)$ & \\
\hline Posterior & $6(37.5 \%)$ & $2(50.0 \%)$ & \\
\hline Dome & $9.2(7.6-13.4)$ & $9.9(6.6-11.1)$ & .813 \\
\hline Neck & $5.5(4.4-7.0)$ & $4.5(3.2-8.8)$ & .741 \\
\hline VER & $22.1(13.9-26.1)$ & $25.1(18.5-37.3)$ & .321 \\
\hline \multicolumn{4}{|l|}{ Use of stent } \\
\hline No & $9(56.3 \%)$ & $2(50.0 \%)$ & .822 \\
\hline Yes & $7(43.7 \%)$ & $2(50.0 \%)$ & \\
\hline \multicolumn{4}{|c|}{$\begin{array}{l}\text { Type of recanalization } \\
\text { on final DSA }\end{array}$} \\
\hline$\|+\| l l a$ & $10(62.5 \%)$ & $0(0.0 \%)$ & $.025^{\mathrm{b}}$ \\
\hline IIIb & $6(37.5 \%)$ & 4 (100.0\%) & \\
\hline \multicolumn{4}{|c|}{ Aneurysm growth } \\
\hline No & $13(81.3 \%)$ & $3(75.0 \%)$ & .780 \\
\hline Yes & $3(18.7 \%)$ & $1(25.0 \%)$ & \\
\hline
\end{tabular}

Note:-ICA indicates ICA other than ICA-PcomA; VA, vertebral artery; BA, basilar artery; SCA, superior cerebellar artery; VER, volume embolization ratio; Posterior, posterior circulation including the VA, BA-SCA, and BAbifurcation.

${ }^{a}$ Data are recanalized aneurysms in the unruptured group $(n=38)$ : Twenty of 38 recanalized aneurysms were untreated. Among 20 untreated recanalized aneurysms, 16 aneurysms unruptured and 4 aneurysms ruptured.

${ }^{\mathrm{b}}$ Statistical significance.

Table 6: Factors associated with rupture after coil embolization in untreated recanalized aneurysms in the ruptured group ${ }^{a}$

\begin{tabular}{|c|c|c|c|}
\hline & \multicolumn{3}{|c|}{$\begin{array}{l}\text { Untreated Recanalized Aneurysms } \\
\qquad(n=21)\end{array}$} \\
\hline & $\begin{array}{l}\text { Unruptured } \\
(n=17)\end{array}$ & $\begin{array}{c}\text { Ruptured } \\
(n=4)\end{array}$ & $\begin{array}{c}P \\
\text { Value }\end{array}$ \\
\hline Age (yr) & $62.0(44.5-78.0)$ & $55.5(47.5-75.5)$ & .929 \\
\hline \multicolumn{4}{|l|}{ Sex } \\
\hline Male & $6(35.3 \%)$ & $1(25.0 \%)$ & .694 \\
\hline Female & $11(64.7 \%)$ & $3(75.0 \%)$ & \\
\hline \multicolumn{4}{|l|}{ Location } \\
\hline ICA & $3(17.7 \%)$ & $0(0.0 \%)$ & .628 \\
\hline ICA-PcomA & 9 (52.9\%) & $2(50.0 \%)$ & \\
\hline AcomA & $4(23.5 \%)$ & $2(50.0 \%)$ & \\
\hline Posterior & $1(5.9 \%)$ & $0(0.0 \%)$ & \\
\hline Dome & $6.2(5.2-8.7)$ & $9.4(5.3-14.4)$ & .347 \\
\hline Neck & $3.2(2.5-4.6)$ & $5.2(3.6-9.1)$ & .066 \\
\hline VER & $24.9(21.3-29.5)$ & $25.5(16.7-28.5)$ & .741 \\
\hline \multicolumn{4}{|l|}{ Use of stent } \\
\hline No & 17 (100.0\%) & $4(100.0 \%)$ & - \\
\hline Yes & $0(0.0 \%)$ & $0(0.0 \%)$ & \\
\hline \multicolumn{4}{|c|}{$\begin{array}{l}\text { Type of recanalization } \\
\text { on final DSA }\end{array}$} \\
\hline II+IIIa & 11 (64.7\%) & $0(0.0 \%)$ & $.020^{\mathrm{b}}$ \\
\hline IIIb & $6(35.3 \%)$ & $4(100.0 \%)$ & \\
\hline \multicolumn{4}{|c|}{ Aneurysm growth } \\
\hline No & $16(94.1 \%)$ & 4 (100.0\%) & .619 \\
\hline Yes & $1(5.9 \%)$ & $0(0.0 \%)$ & \\
\hline
\end{tabular}

Note:- - indicates not available.

${ }^{\text {a }}$ Data are recanalized aneurysms in the ruptured group ( $\left.n=37\right)$ : Twenty-one of 37 recanalized aneurysms were untreated. Among 21 untreated recanalized aneurysms, 17 aneurysms unruptured and 4 aneurysms ruptured.

${ }^{\mathrm{b}}$ Statistical significance. respectively. In the unruptured group, 4 class IIIb recanalized aneurysms ruptured of the 20 untreated recanalized aneurysms, and there was a significant difference in the frequency of rupture between classes II and IIIa $(P=.025)$.

In the ruptured group, 4 class IIIb recanalized aneurysms ruptured of the 21 untreated recanalized aneurysms, and there was a trend toward a larger median aneurysm neck diameter in the ruptured recanalized aneurysms $(5.2 \mathrm{~mm})$ compared with the unruptured recanalized aneurysms (3.2 mm; $P=.066)$. Class IIIb recanalized aneurysms ruptured significantly more frequently than classes II and IIIa $(P=.020)$.

\section{Rupture of Recanalized Aneurysms}

The cases of ruptured recanalized aneurysm are summarized in the On-line Table. The DSA findings of ruptured recanalized aneurysms in the unruptured and ruptured groups are shown in Figs 2 and 3, respectively. In patient 4 in the unruptured group, DSA could not be performed when the recanalized aneurysm ruptured. Thus, the MRA findings are shown instead. In the unruptured group, 4 recanalized aneurysms ruptured. In patient 1 with a large basilar artery-bifurcation aneurysm, the type of recanalization changed from class II to IIIb, and the aneurysm ruptured at 8 months after coil embolization. In patient 2 with an ICA-postrior communicating artery (PcomA) aneurysm, patient 3 with an ICA-paraclinoid aneurysm, and patient 4 with a large basilar artery-bifurcation aneurysm, the type of recanalization was class IIIb, and the aneurysms ruptured with a new bleb formation at 76,2 , and 24 months after coil embolization, respectively. All 4 patients with ruptured recanalized aneurysms were receiving continued antiplatelet therapy at the time of rupture.

In the ruptured group, 4 recanalized aneurysms ruptured. In patients 1 and 2, both with an anterior communicating artery (AcomA) aneurysm, the type of recanalization changed from class II to IIIb, and both aneurysms ruptured with formation of a new bleb at 1 month after coil embolization. In patients 3 and 4 , both with an ICA-PcomA aneurysm, the type of recanalization was class IIIb, and the aneurysms ruptured at 29 and 7 months after coil embolization, respectively. All 4 patients with ruptured recanalized aneurysms were receiving continued antiplatelet therapy at the time of rupture. Recanalized aneurysms in the ruptured group tended to rupture earlier than those in the unruptured group.

\section{DISCUSSION}

The epidemiology, natural history, management options, and familial screening of unruptured aneurysm are well-established. ${ }^{7-11}$ Several studies have also reported treatment outcomes for ruptured 


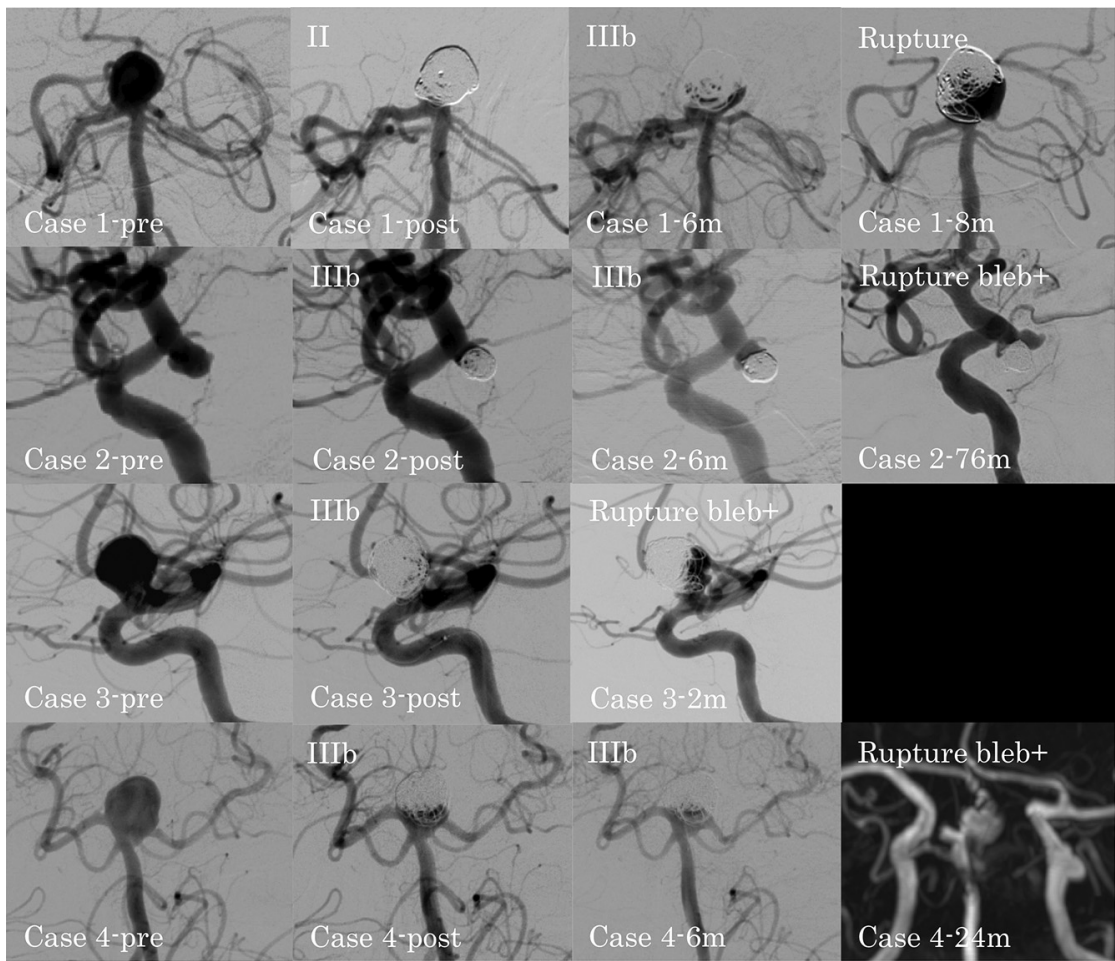

FIG 2. DSA findings for ruptured recanalized aneurysms in the unruptured group. Case 1-pre: preately after the procedure; case $1-6 \mathrm{~m}$ : class $\mathrm{IIl} \mathrm{b}$ recanalization at 6 months after the procedure; case 1-8m: ruptured recanalized aneurysm at 8 months after the procedure; case 2-pre: preprocedural ICA-posterior communicating artery aneurysm; case 2-post: class IIIb aneurysm occlusion immediately after the procedure; case $2-6 \mathrm{~m}$ : progression of the class IIIb recanalization at 6 months after the procedure; case $2-76 \mathrm{~m}$ : ruptured recanalized aneurysm with a new bleb at 76 months after the procedure; case 3-pre: preprocedural paraclinoid-ICA aneurysm; case 3-post: class IIIb aneurysm occlusion immediately after the procedure; case $3-2 \mathrm{~m}$ : ruptured recanalized aneurysm with a new bleb at 2 months after the procedure; case 4-pre: preprocedural basilar artery-bifurcation aneurysm; case 4-post: class IIIb aneurysm occlusion immediately after the procedure; case 4-6m: no change at 6 months after the procedure; case 4-24m: MRA shows the ruptured recanalized aneurysm with a new bleb at 24 months after the procedure. procedural basilar artery-bifurcation aneurysm; case 1-post: class II aneurysm occlusion immedi-

impingement and subsequent wall shear stress increments may lead to recanalization. ${ }^{19}$

Recanalization is a risk factor for rupture of coiled aneurysms because major recanalization can result in aneurysm rupture. However, not all recanalized aneurysms rupture, and the risk of rupture seems to depend on the type of recanalization. The Modified Raymond-Roy classification is an indicator of how aneurysms are occluded, and it can be used to predict progressive occlusion or recurrence. ${ }^{6}$ Because the type of occlusion is a predictor of recanalization, the types of occlusion and recanalization may be predictors of rupture of coiled aneurysms. In the present study, although the aneurysm neck diameter of the ruptured recanalized aneurysms tended to be larger than that of the unruptured recanalized aneurysms in the ruptured group $(P=$ .066), the type of recanalization was the only significant factor in both the unruptured $(P=.025)$ and ruptured $(P=.020)$ groups. There was no rupture of coiled aneurysms with class II and IIIa recanalization (ie, no contrast along the aneurysm wall). However, 4 recanalized aneurysms with class IIIb recanalization (ie, contrast along the aneurysm wall) ruptured in each group. Although there were few ruptured aneurysms and statistical evaluation was insufficient, the present study has important information regarding aneurysms. $^{1,12-14}$ Aneurysms are widely treated by endovascular coiling, which has become the standard treatment because of its clinical efficacy. ${ }^{1,2}$ However, recanalization is an important problem that can occur after coil embolization and can result in aneurysm rupture. Although numerous studies have evaluated recanalization in unruptured aneurysms after coil embolization, there are insufficient data on how recanalized aneurysms rupture. In addition, in ruptured aneurysms, although long-term follow-up data from the International Subarachnoid Aneurysm Trial (ISAT) showed that the risk of rerupture of coiled aneurysms was $0.156 \%,{ }^{15}$ there are no detailed data on how the coiled aneurysms recanalized and ruptured. Thus, the present study evaluated whether the type of recanalization affected the risk of aneurysm rupture.

In general, large aneurysms are more likely to recanalize than small aneurysms, ${ }^{5,16-18}$ and recanalization rates after stent-assisted coil embolization are lower than those after simple coil embolization. ${ }^{19-21}$ In addition, recanalization is affected by hemodynamic force. $^{22}$ Computational fluid dynamics studies have shown that maximum wall shear stress increases at sites of blood flow impingement near remnant necks. ${ }^{23}$ This repetitive flow how the occlusion and recanalization of coiled aneurysms affected the risk of rupture.

A previous study reported that the risk factors for early recanalization of coiled aneurysms within 6 months included posterior circulation aneurysms, $\mathrm{SAH}$ presentation, a second coiling procedure for recanalization, and an aneurysm of $>7 \mathrm{~mm} .{ }^{18}$ In addition, longterm follow-up is recommended even for aneurysms of 4-7 mm because of the risk of late recanalization. ${ }^{18}$ In the present study, recanalized aneurysms in the ruptured group tended to rupture earlier than those in the unruptured group. In our institution, on the basis of our experience, follow-up DSA was scheduled at 6 months after treatment for unruptured aneurysms; for ruptured aneurysms, follow-up DSA was scheduled at 1 week after treatment to evaluate vasospasm and at 1 month after treatment to detect early recanalization. The recanalized aneurysms in patients 1 and 2 in the ruptured group ruptured at 1 month after treatment (just before the scheduled follow-up DSA).

In the present study, most retreatments for recanalization in the ruptured group were performed at $1-6$ months after the initial treatment. Follow-up DSA within 1 month can prevent the rupture 


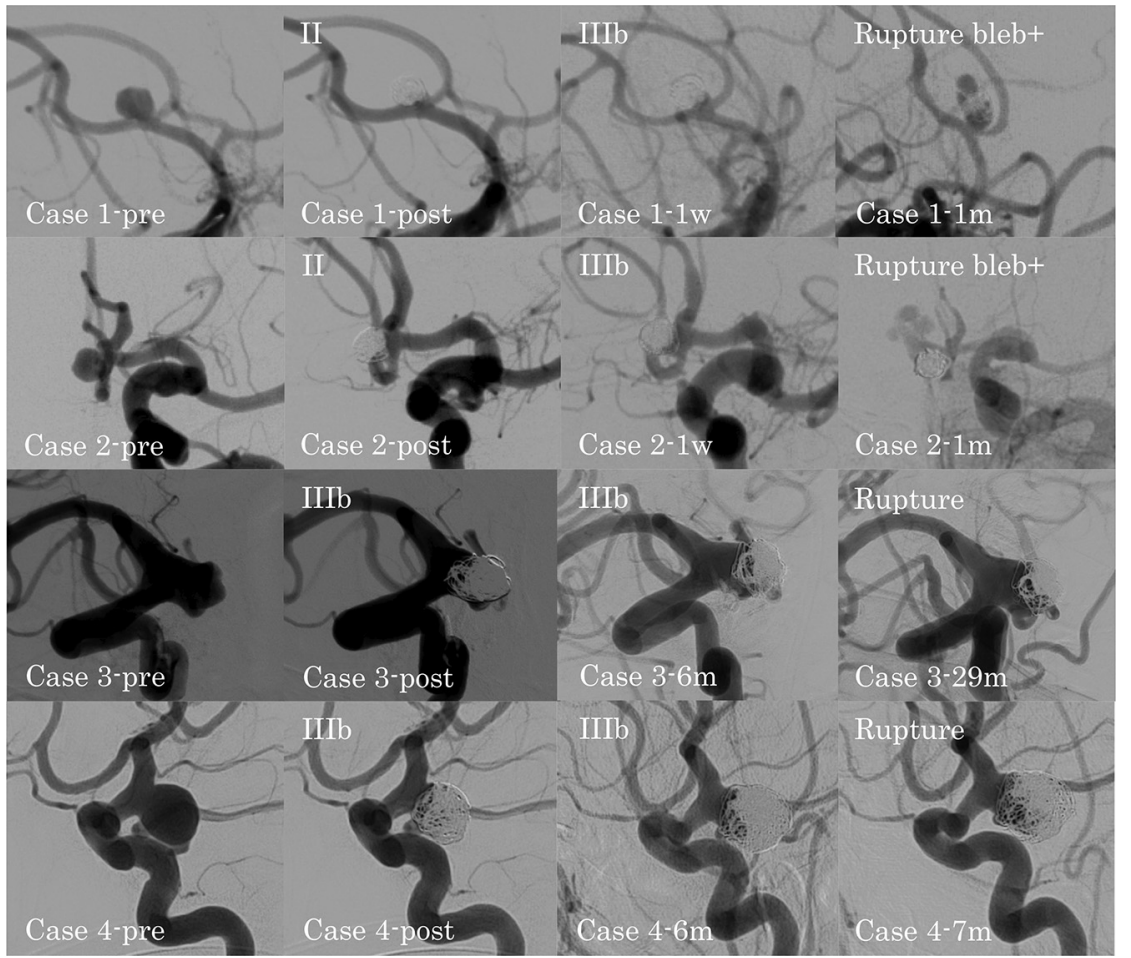

FIG 3. DSA findings for ruptured recanalized aneurysms in the ruptured group. Case 1-pre: preprocedural anterior communicating artery aneurysm; case 1-post: class II aneurysm occlusion immediately after the procedure; case 1-1w: class IIIb recanalization at 1week after the procedure; case 1-1m: ruptured recanalized aneurysm with a new bleb at 1 month after the procedure; case 2-pre: preprocedural anterior communicating artery aneurysm; case 2-post: class II aneurysm occlusion immediately after the procedure; case 2-lw: class IIIb recanalization at 1 week after the procedure; case 2-1m: ruptured recanalized aneurysm with a new bleb at 1 month after the procedure; case 3-pre: preprocedural ICA-posterior communicating artery aneurysm; case 3-post: class $\mathrm{IIIb}$ aneurysm occlusion immediately after the procedure; case 3-6m: progression of the class IIIb recanalization at 6 months after the procedure; case 3-29m: ruptured recanalized aneurysm at 29 months after the procedure; case 4-pre: preprocedural ICA-posterior communicating artery aneurysm; case 4-post: class IIIb aneurysm occlusion immediately after the procedure; case 4$6 \mathrm{~m}$ : progression of the class IIIb recanalization at 6 months after the procedure; case $4-7 \mathrm{~m}$ : ruptured recanalized aneurysm at 7 months after the procedure.

of some recanalized aneurysms. For unruptured aneurysms, follow-up DSA at 6 months after coil embolization is considered reasonable. Compared with the ruptured group, the timing of coiled aneurysm rupture in the unruptured group tended to be later in the present study. Most retreatments for recanalization in the unruptured group were performed at 6 months to 1 year after the initial treatment. Although retreatment at this time can prevent the rupture of recanalized aneurysms, there are rare exceptions that rupture shortly after coil embolization: For example, the unruptured aneurysm after coil embolization in patient 3 ruptured at 2 months after treatment. In addition, there were cases in both the unruptured and ruptured groups in which the coiled aneurysms ruptured during long-term follow-up. Coiled aneurysms with class IIIb recanalization should undergo early retreatment because of the high risk of rupture. Although coiled aneurysms with class II or IIIa recanalization should also be retreated if possible, these aneurysms can be treated with conservative therapy because of the low risk of rupture. However, class II or IIIa recanalization can progress into class IIIb recanalization. Thus, follow-up examinations are essential.
Periprocedural antiplatelet therapy was associated with a low risk of symptomatic thromboembolic events after coil embolization for aneurysms. $^{24}$ In the present study, all patients with ruptured recanalized aneurysms were receiving continued antiplatelet therapy at the time of rupture. In particular, long-term dual-antiplatelet therapy was continued, considering the thromboembolic event in patient 4 in the uruptured group. Long-term singleantiplatelet therapy was also continued in patient 2 in the unruptured group and in patient 3 in the ruptured group. Although it is unclear whether antiplatelet therapy in the present cases could influence the rupture of recanalized aneurysms, indiscriminate continuation of antiplatelet therapy should be avoided.

The risk of rupture for aneurysms with growth is 12 times higher than that for aneurysms without growth. ${ }^{25}$ In the present study, although some coiled aneurysms showed aneurysm growth and the appearance of new blebs, there were no significant differences in aneurysm growth in the unruptured $(P=.780)$ and ruptured $(P=.619)$ groups. The appearance of new blebs was also not a significant risk factor for rupture of recanalized aneurysms. However, all aneurysms with the appearance of new blebs on follow-up DSA were retreated, and the appearance of new blebs was detected in 3 of 4 ruptured recanalized aneurysms in the unruptured group and in 2 of 4 ruptured recanalized aneurysms in the ruptured group at the time of rupture. Although it is difficult to detect the appearance of new blebs on follow-up DSA because aneurysms with formation of new blebs can rupture early, the appearance of new blebs can be a risk factor for rupture of recanalized aneurysms and thus must not be overlooked. Additionally, the appearance of new blebs both on follow-up DSA and at the time of rupture was identified only in coiled aneurysms with class IIIb recanalization; this finding may be because blood flow along the aneurysm wall can form new blebs. In recanalized aneurysms, the type of recanalization can be important because class IIIb recanalization can result in the appearance of new blebs, which may be a risk factor for early rupture of recanalized aneurysms.

\section{Study Limitations}

The present study was a nonrandomized retrospective observation study, though the series comprised consecutive cases. In addition, 
interpretation of the radiographic data was performed in a nonblinded manner. Although there were 4 cases of ruptured recanalized aneurysms in both the unruptured and ruptured groups, the number of ruptured recanalized aneurysms was small. Thus, statistical multivariate analysis could not be performed, though multiple factors can be related to rupture of recanalized aneurysms. Because the ruptured group included many severe cases that could not be followed up at our institution, there was also a lack of cases with sufficient data. Furthermore, because retreatment was generally performed in cases in which retreatment for recanalized aneurysms was possible and the patient provided consent, the true course of recanalized aneurysms leading to rupture without retreatment remains unclear.

\section{CONCLUSIONS}

The present study determined the type of recanalized aneurysm at risk of rupture on the basis of our experience. The types of aneurysm occlusion and recanalization are predictors of the rupture of coiled aneurysms. Coiled aneurysms with class IIIb recanalization should undergo early retreatment because of the high risk of rupture.

\section{ACKNOWLEDGMENTS}

We thank Kelly Zammit, BVSc, from Edanz Editing (www. edanzediting.com/ac), for editing a draft of the manuscript.

Disclosures: Hirotoshi Imamura-UNRELATED: Payment for Lectures Including Service on Speakers Bureaus: Medtronic. Nobuyuki Sakai-UNRELATED: Grants/ Grants Pending: Terumo, Medtronic, Comments: modest*; Payment for Lectures Including Service on Speakers Bureaus: Biomedical Solutions, Stryker, Terumo, Comments: modest. *Money paid to the institution.

\section{REFERENCES}

1. Molyneux A, Kerr R, Stratton I, et al; International Subarachnoid Aneurysm Trial (ISAT) Collaborative Group. International Subarachnoid Aneurysm Trial (ISAT) of neurosurgical clipping versus endovascular coiling in $\mathbf{2 1 4 3}$ patients with ruptured intracranial aneurysms: a randomised trial. Lancet 2002;360:1267-74 CrossRef Medline

2. Lin N, Cahill KS, Frerichs KU, et al. Treatment of ruptured and unruptured cerebral aneurysms in the USA: a paradigm shift. $J$ NeuroIntervent Surg 2018;10:169-76 CrossRef Medline

3. Ries T, Siemonsen S, Thomalla G, et al. Long-term follow-up of cerebral aneurysms after endovascular therapy-prediction and outcome of retreatment. AJNR Am J Neuroradiol 2007;28:1755-61 CrossRef Medline

4. Zhang Q, Jing L, Liu J, et al. Predisposing factors for recanalization of cerebral aneurysms after endovascular embolization: a multivariate study. J Neurointerv Surg 2018;10:252-57 CrossRef Medline

5. Jeon JP, Cho YD, Rhim JK, et al. Extended monitoring of coiled aneurysms completely occluded at 6-month follow-up: late recanalization rate and related risk factors. Eur Radiol 2016;26:3319-26 CrossRef Medline

6. Mascitelli JR, Moyle H, Oermann EK, et al. An update to the Raymond-Roy occlusion classification of intracranial aneurysms treated with coil embolization. J Neurointervent Surg 2015;7:496502 CrossRef Medline
7. Wiebers DO, Whisnant JP, Huston J 3rd, et al. Unruptured intracranial aneurysms: natural history, clinical outcome, and risks of surgical and endovascular treatment. Lancet 2003;362:103-10 CrossRef

8. Sonobe M, Yamazaki T, Yonekura M, et al. Small unruptured intracranial aneurysm verification study: SUAVe study, Japan. Stroke 2010;41:1969-77 CrossRef

9. Morita A, Kirino T, Hashi K, et al. The natural course of unruptured cerebral aneurysms in a Japanese cohort. N Engl J Med 2012;366:247482 CrossRef Medline

10. Brown RD, Broderick JP. Unruptured intracranial aneurysms: epidemiology, natural history, management options, and familial screening. Lancet Neurol 2014;13:393-404 CrossRef Medline

11. Darsaut TE, Findlay JM, Magro E, et al. Surgical clipping or endovascular coiling for unruptured intracranial aneurysms: a pragmatic randomised trial. J Neurol Neurosurg Psychiatry 2017;88:66368 CrossRef Medline

12. CARAT Investigators. Rates of delayed rebleeding from intracranial aneurysms are low after surgical and endovascular treatment. Stroke 2006;37:1437-42 Medline

13. McDougall CG, Spetzler RF, Zabramski JM, et al. The Barrow Ruptured Aneurysm Trial. J Neurosurg 2012;116:135-44 CrossRef Medline

14. Lindgren A, Vergouwen MD, van der Schaaf IC, et al. Endovascular coiling versus neurosurgical clipping for people with aneurysmal subarachnoid hemorrhage. Stroke 2019;50:e102 CrossRef

15. Molyneux AJ, Kerr RS, Birks J, et al. Risk of recurrent subarachnoid haemorrhage, death, or dependence and standardised mortality ratios after clipping or coiling of an intracranial aneurysm in the International Subarachnoid Aneurysm Trial (ISAT): long-term follow-up. Lancet Neurol 2009;8:427-33 CrossRef Medline

16. Cognard C, Weill A, Spelle L, et al. Long-term angiographic followup of 169 intracranial berry aneurysms occluded with detachable coils. Radiology 1999;212:348-56 CrossRef Medline

17. Ogilvy CS, Chua MH, Fusco MR, et al. Validation of a system to predict recanalization after endovascular treatment of intracranial aneurysms. Neurosurgery 2015;77:168-73 CrossRef Medline

18. Jeon JP, Cho YD, Yoo DH, et al. Risk factor analysis of recanalization timing in coiled aneurysms: early versus late recanalization. AJNR Am J Neuroradiol 2017;38:1765-70 CrossRef Medline

19. Luo CB, Teng MMH, Chang FC, et al. Stent-assisted coil embolization of intracranial aneurysms: a single center experience. $J$ Chin Med Assoc 2012;75:322-28 CrossRef Medline

20. Hwang SK, Hwang G, Bang JS, et al. Endovascular Enterprise stentassisted coil embolization for wide-necked unruptured intracranial aneurysms. J Clin Neurosci 2013;20:1276-79 CrossRef Medline

21. Jeon JP, Cho YD, Rhim JK, et al. Fate of coiled aneurysms with minor recanalization at 6 months: rate of progression to further recanalization and related risk factors. AJNR Am J Neuroradiol 2016;37:1490-95 CrossRef Medline

22. Park W, Song Y, Park KJ, et al. Hemodynamic characteristics regarding recanalization of completely coiled aneurysms: computational fluid dynamic analysis using virtual models comparison. Neurointervention 2016;11:30-36 CrossRef Medline

23. Ortega J, Hartman J, Rodriguez J, et al. Post-treatment hemodynamics of a basilar aneurysm and bifurcation. Ann Biomed Eng 2008;36:153146 CrossRef Medline

24. Almekhlafi MA, Al Sultan AS, Kuczynski AM, et al. Antiplatelet therapy for prevention of thromboembolic complications in coilingonly procedures for unruptured brain aneurysms. J Neurointerv Surg 2020;12:298-302 CrossRef Medline

25. Villablanca JP, Duckwiler GR, Jahan R, et al. Natural history of asymptomatic unruptured cerebral aneurysms evaluated at CT angiography: growth and rupture incidence and correlation with epidemiologic risk factors. Radiology 2013;269:258-65 CrossRef Medline 